\section{Ravens in the United States}

ON p. 336 of NATURE for February 7, Manhattan asks a question about "ravens." I do not propose to answer his question, but to state a fact. I was raised from boyhood to manhood in Tioga Co., Penn., and in my boyhood days, when the primeval forests were broken only by the recent settler's small patch scattered here and there along the valleys, the raven was a; common as the crow; nor could the one ever be mistaken for the other. Before I had attained the years of manhood, however, the raven had become a rara avis, while the crow, on the contrary, had become vastly more abundant. The bald-eagle, and the fish-hawk, too, were then very often seen, now seldom or never. Other birds could be added to the list if desirable. The question, why? is not so easily disposed of as it is to state the fact. Should one be dispostd to answer by saying the rifle, it would be pertinent to reply that the rifle was just as active against the crow, the common hen-hawk, and the crow-blackbird, as it was against the raven, the fish-hawk, and the bald-eagle ; but these latter birds have all disappeared, while, in spite of the rifle, the former have increased. We must look deeper for the cause.

Washington, D.C., March 3

In answer to the query of your correspondent "Manhattan," who writes from New York, under date of Jan. I I, concerning the prevalence of ravens in the United States, I would like to remark that ravens quite replace the crow in Nevada. I have never seen them here in the east. Mr. Ridgway who was with me in 1867-68 could give you much valuable information in regard to their habits and range.

W. W. BAILEX

Brown University, Providence, R.I. (U.S.As.), March I

\section{Thread-twisting}

IN NATURE, January 3 I (p. 305), I read some remarks by Prof. E. B. Tylor on a "rude method of maling thread by rolling palm or grass fibre into a twist with the palin of the hand on the thigh," which Prof. Tylor regards as a "savage art" of old native tribes of Guiana, who were thigh-twisters. I have often seen shoemakers when at work prepare their threads by twisting them on the thigh with the palm of the hand. May this practice be one which has survived from a barbarous period?

Truro, March 14

\title{
BICYCLES AND TRICYCLES IN THEORY AND IN PRACTICE ${ }^{1}$
}

WHEN I was honoured by the invitation to give this discourse on bicycles and tricycles, I felt that many might think the subject to be trivial, altogether unworthy of the attention of reasonable or scientific people, and totally unfit to be treated seriously before so highly cultured an audience as usually assembles in this Institution. On the other hand, I felt myself that this view was entirely a mistaken one, that the subject is one of real and growing importance, one of great scientific interest, and, above all, one of the most delightful to deal with that a lecturer could wish to have suggested to him.

It is quite unnecessary for me to bring forward statistics to show how great a hold this so-called new method of locomotion has taken upon people of all classes: the streets of London, the roads and lanes in all parts of the country, testify more forcibly than any words of mine can do to what enormous numbers there are who now make use of cycles of one sort or other for plcasure or for the purposes of business.

Not only has the newly developing trade brought pro sperity to towns whose manufactures were dying a natura death, but the requirements of cyclists have given rise to a series of minor industries, themselves of great importance. Riders of bicycles and tricycles come along so silently that instruments of warning have been devised. There are bells that jingle, bells that ring, whistles, bugles, and a fiendish born which will utter anything from a

I I ecture delivered by C. Vernon Boys, A R.S.M., at the Royal Institution, March 7 .

gentle remonstrance to a wild, unearthly shriek. Lamps, tyres, saddles, seats, springs, \&c., are made in unending variety ; these form the endless subject of animated conversation in which the cyclist so frequently indulges. Cyclometers or instruments for measuring the distance run are also much used. Some show the number of revolutions made by the wheel, from which the distance can be found by a simple calculation; others indicate the distance in miles. There is on the table a home-made one of mine with a luminous face which at the end of every mile gives the rider a word of encouragement; it now indicates that a mile is nearly complete; in another turn or two you will all hear it speak.

Cyclists have a literature of their own. There are about a dozen papers wholly or largely devoted to the sport. They can even insure themselves and their machines against injury by accident in a company of their own.

The greatest and by far the most important growth is the Cyclists' Touring Club, a gigantic club to which every right-minded rider in the country belongs. This club has done more to make touring practically enjoyable than could have been thought possible when it began its labours. Railway companies have with few exceptions consented to take cycles at a fixed and reasonable rate; in almost every town in the country an agreement has been made with the leading, or at any rate a first-class, hotel, in virtue of which the touring member may be sure of meeting with courtesy and attention for himself and with clean quarters and an intelligent groom for his horse, instead of finding himself as hitherto a strange being in a strange place at the mercy of some indifferent or exorbitant landlord. In consequence of this, thousands now spend their holidays riding over and admiring the beauties of our own country instead of being dragged with a party of tourists through the streets and building; of a foreign town. Of the delightful nature of a cycling tour I can speak from grateful experience; last autumn alone I travelled nearly 1500 miles, meeting on my way with almost every variety of beauty that the scenery of this country affords. Wherever I went I felt the beneficial influence of the C.T.C., as the touring club is called. At all the hotels - our headquarters - at which I stopped, $I$ found the most sanguine wishes of the club amply fulfilled, our wants understood and provided for.

The C.T.C. have also done a great service in providing us with a uniform which has been proved to be as near perfection as possible. They have also designed a ladies' cycling dress, which can be seen in the library.

Though touring in the country is the perfection of our art, town riding has its advantages. I, in common with a fair number, ride daily to and from my work no matter what the weather may be : rain, snow, wind, or hail, cycling affords the pleasantest means of crossing London. Instead of waiting in draughty railway stations, of catching cold outside or being stewed inside omnibuses, or of being smoked in the Underground Railway, we, the regular cyclists, look forward to our daily ride with pleasure, for the healthy exercise, the continuous necessity of watching the traffic and avoiding ever-approaching danger, form between them a relief from mental worry or business anxiety which we alone can appreciate.

Of the dangers of the streets I have little to say: the regulation of the traffic by the police, and the considera tion of drivers, though they are not in general too fond of us, make danger in the quarter from which it might be expected very remote. Our chief difficulty is due to the irregular and utterly linaccountable movements of pedestrians, whose carelessness kecps us in a continual state of anxiety.

There remains one point of the utmost importance on which I would say a few word;, I refer to the effect of cycling on our general heaith. About a year ago there appeared in the Lancet an aricle condemning in no 
measured terms the evils likely to result from the development of this new craze, in which, as far as I remember, it was stated that we are now sowing the seeds of a series of new diseases, the symptoms of which will only appear possibly in years to come. I would not for a moment question the accuracy of opinion held by any professional man; whether this is or is not the case I cannot tell; however, I may mention that the only sumptoms which I have so far discovered in myself are an improved appetite, increased weight, and a general robustness to which was formerly a perfect stranger. Having, I trust, succeeded in showing that the advantages offered to riders are sufficient to account for the rapid development of cycling, that it is in fact no mere temporary craze, I shall now proceed to consider the theory and construction of the various machines at present known.

From the hobby-horse to the bone-shaker, and from the bone-shaker to the bicycle, the steps are so simple and obvious that it is quite unnecessary for me to trace them. It is also needless for me to describe the modern bicycle: every one must be familiar with it, every one must have seen the ridiculous zigzag of the beginner, and have admired the graceful gliding of an accomplished rider. Of the theory of the balance little need be said; anything supported in a mere line, in unstable equilibrium as it is called, must fall one way or the other. The machine and rider would of necessity capsize if some action of recovery were not possible. To whichever side the machine shows any inclination, to that side the rider instinctively directs it. By this means the tendency to fall to one side is balanced by the property of the rider to continue moving in a straight line, and so to go over on the other side. This action of recovery is always overdone, so that a second turn in the opposite direction must follow. Hence the extraordinary path traced by the beginner. Even with the most skilful rider, though he appears to travel in a perfectly straight line, a slightly sinuous course is essential, as the highly characteristic track left on the road indicates. If anything should happen to check this slightly serpentine motion, as, for instance, occurs when the driving-wheel drops in the groove of a tram-line, the balance at once becomes impossible, and the rider is compelled to dismount.

The extraordinary stability of the bicycle at a bigh speed depends largely on the gyroscopic action of the wheels. On the table is a top supported in a ring which is free to move how it pleases. So long as the top is spinning the ring is as rigid as a block; on stopping it, the freedom of the support is at once apparent.

It is a marvel to many how anything so light, how anything so delicate, can carry the weight or can travel at the speed so common without utterly collapsing. The wheels especially attract attention. In a boop no one part can be pushed in unless some other part can go out. A bicycle wheel is a hoop in which every part is prevented from going out by the tension of the spokes. To give the wheel lateral stability, the spokes are carried not to the centre, but to the two ends of the hub, thus lying on two cones. Such a wheel is abundantly strong in its own plane: it can withstand the jars and shocks of a bad road without a groan, but once subject it to serious side strain, such as I can with ease put upon it with a jerk of my wrists, and the wheel will crumple up like an umbrella in a storm. Till this year there has been no change in the principle of construction, though in detail many improvements have been carried out and are largely adopted. By the use of hollow rims a stiffer and lighter wheel can be made; thick-ended, crossed and laced spokes are employed, and other details modified. Essentially, however, the "spider" wheel as a structure is the same as it was when first introduced. Suddenly two radical changes are presented to us. Mr. Otto, whose great work I shall describe in its proper place, has devised a wheel on a new system, in which the spokes that form the structure lie in the plane of the rim, in which position they are best able to withstand direct shocks. Such a wheel would be urstable, but requires very little to keep it true. Uelicate spokes, not screwed up very tight, are therefore placed on either side, so that a side-strain is met by the whole strength of the spokes on one side, which are not as hitherto weakened by the pull of the spokes on the other. On this system much narrower wheels can be made than was possible before. The other change, due to the same inventor, is still more striking. He has found, contrary to the opinion of every one, that wheels, either of his narrow type or of the usual form, can be made and will remain true when the spokes are made elastic by being bent into a wavy or slightly spiral form. If only these wheels will stard the test of time-and I see no reason why they should not-one of the greatest discomforts and possible causes of injury from which the cyclist suffersthe vibration and jolting due to a bad road-will have been removed.

The bearings in a bicycle are perhaps more to be admired than any single part. Instead of allowing the axle to slide round in its bearings, hard steel rollers or balls are introduced, so that the parts which are pressed together roll over and do not slide upon one another. Any one who has trodden on a roller or a marble must have found in a possibly unpleasant manner the great difference between rolling and sliding friction. I can now give for the first time the result of an experiment only completed this morning, which shows the extraordinary perfection to which this class of work has attained. I have observed how much a new set of balls which I obtained direct from the well-known maker, Mr. Bown, has lost in weight in travelling 1000 miles in my machine. Every 200 miles I cleaned and weighed the balls with all the care and accuracy that the resources of a physicai laboratory will permit. The set of twelve, when new, weighed 25.80400 grm. After 1000 miles, they weighed 25.80088 grm., the loss being 3.12 mgrm., which is equal to $\mathrm{r} / 20^{\circ} 8$ grain, that is, in rumning 1000 miles, each bal! lost $1 / 250$ grain. This corresponds to a wear of only I/I 58,000 inch off the surface. At this rate of wear$3.12 \mathrm{mgrm}$. per 1000 miles-the balls would lose only $\mathbf{I} / 34^{.} 3$ of their weight in travelling as far as from here to the moon.

The twelve balls, after the first 200 miles, each weighed in grammes as follows. The loss of each in running 600 miles is appended :-

\begin{tabular}{|c|c|c|c|c|c|}
\hline eight in grm. & & s in 600 miles & Weight in grm. & \multirow{2}{*}{\multicolumn{2}{|c|}{$\begin{array}{c}\text { Loss in } 600 \text { miles } \\
.00020\end{array}$}} \\
\hline $2 \cdot 16605$ & $\cdots$ & ' $c 0050$ & 2.14725 & & \\
\hline 2.16180 & ... & $\cdot 0 \mathrm{CO} 25$ & $2 \cdot 14725$ & $\cdots$ & 00020 \\
\hline $2 \cdot 1555^{\circ}$ & $\cdots$ & ${ }^{\circ} \mathrm{COO} 35$ & $2 \cdot 14700$ & $\ldots$ & 00020 \\
\hline $2 \cdot 15480$ & $\ldots$ & 'cool 5 & $2 \cdot 14500$ & $\ldots$ & ${ }^{\circ} \mathrm{COO} 2 \mathrm{O}$ \\
\hline $2 \cdot 15000$ & $\ldots$ & $.000 \times 5$ & $2 \cdot 14280$ & $\ldots$ & .00025 \\
\hline $2 \cdot 14730$ & $\ldots$ & ${ }^{\circ} \operatorname{coo} 5$ & 2.13875 & $\ldots$ & .00020 \\
\hline
\end{tabular}

I did not weigh each ball on the first and last occasion. However, the wonderfully uniform wear in the intermediate 600 miles speaks well for the $\epsilon$ qual hardness of the balls.

The wear of the dozen during each journey of 200 miles was as follows :-

$\begin{array}{ccc}\text { Miles } & & \text { Wear in grm. } \\ 0-200 & \ldots & \cdot 00055 \\ 200-400 & \ldots & 00070 \\ 400-600 & \ldots & 00055 \\ 600-800 & \ldots & \cdot 00075 \\ 800-1000 & \ldots & 00062\end{array}$

I have given the results of these experiments at length, for I do not think that accurate and systematic observations of the kind have been made before.

We may consider, then, that the balls are practically indestructible. Knowing this, Mr. Trigwell has applied the ball-bearing to the construction of the "head" of the bicycle, not so much with the view of diminishing the 
friction there, but of preventing wear in a place where any shake is highly objectionable. One of his ball-heads is on the table.

The frame of the bicycle, consisting merely of the fork and backbone, is made of thin steel tube, the type of all that is light and strong. Indiarubber, besides being used for the tyres of all machines, has been worked into every part of the structure to diminish, so far as is possible, that perpetual and wearying vibration of which al bicyclists so bitterly complain. The number of improvements in every detail is so great that any attempt to enumerate them is out of the question. Suffice it to say that the modern bicycle is the perfection of all that is perfect as a machine for racing, as a machine for hurrying over good and level roads nothing can approach it. Unfortunately, however, there is ever present danger, and danger of the most objectionable sort, for the most skilful rider knows too well that should he strike a stone of even an ordinary size he must expect to be pitched over the handles, and come with a crash to the ground. It is true that in general no harm is done, but such a fall may bring any one to a sudden and horrible end.

Many haveattempted, while still retaining the advantages of the bicycle, to make these involuntary headers impossible by modifying in some way its construction. One of the earliest attempts in this direction is well named the "Extraordinary." On it the rider is placed much further behind the main wheel, but can still employ his weight to advantage, as the treadles are placed below him and are connected by levers with the cranks. In another safety bicycle a third wheel is carried in front, just above the ground, so as to resist at once any tendency to tilt forward. In another type much smaller wheels are employed, and the feet, now nearer the ground, are connected with the cranks, by levers in the "Facile," or by a hanging pedal in the "Sun and Planet." There is a bicycle with two large wheels-one in front of the otherwhich two can ride, which should be both safe and rapid.

By far the most curious and utterly unintelligible of all machines of the bicycle type is Mr. Burstow's "Centrecycle." So incomprehensible did this machine seem to me that I took the trouble one afternoon last week to ride to Horsham to see it in its native place. A careful examination has convinced me that it is not only correct in its design, but that it is in many respects the most wonderful cycle at present made. There is on the table a model Plympton skate. When this is level, it runs straight; when inclined either way, it wheels around in a manner that was so familiar a few years ago. The four wheels of the Centre-cycle are a counterpart of the four wheels of the skate; when the frame leans either way, they turn in an appropriate manner, or, conversely, when they turn, the machine leans in the proper direction. It might be thought that a thing with five wheels is more nearly allied to a tricycle than to a bicycle; but this is not so, for the Centre-cycle, when ridden skilfully, has rarely more than one wheel on the ground; the leaning to one side in turning a corner (tricycles unfortunately must remain upright), and the general action is essentially that of a bicycle. The great peculiarity of this machine is the power that the rider possesses of raising or lowering any wheel he likes. Now that I have mounted it you will see that I can rest on one, three, four, or five wheels as I please. In consequence of this power of lifting the wheels, a rider can travel over an umbrella without touching it, lifting the wheels as they approach, and dropping them as they pass, after the manner of a caterpillar.

Whatever difficulty I may have had in doing justice to the bicycle, the corresponding difficulty in the case of tricycles is far greater. The number of makers and the variety of their work is so great that it would be sheer madness on my part to attempt to describe all that has been done. Those who wish to see the great variety of detail which chiefly constitutes the difference between one make and another must go to one of the exhibitions of these things which are now so common.

All I shall attempt will be an explanation of the leading principles which are involved in the design of a tricycle. For this purpose it will be necessary for me to mention occasionally some particular machine; but in justice to the hundreds to which I cannot even refer, I wish it to be understood that those named, though typical, are not of necessity better than any other.

Till a few years ago the bicycle was the only velocipede which was worthy of the name. Inventive genius and mechanical skill have given rise to a series of machines on three wheels on which any one can at once sit at ease, and which require but little skill in their management. Men who do not care to risk their necks at the giddy height of the bicyclist, ladies to whom the ordinary bicycle presents difficults which they cannot well surmount, each find in the tricycle the means of obtaining healthy and pleasant exercise, and of enjoying to a certain extent the advantages which the bicycle affords. Thanks to the perfection of the modern tricycle, cycling has become one of the most popular institutions of the day.

It is first necessary to know what combinations of three wheels will, and what will not, roll freely round a curve. The few possible arrangements determine the general forms which a tricycle can take. A wheel can only travel in its own direction; no side motion is possible without the application of considerable force, entailing strain and friction of a most injurious kind. In any combination, then, of three wheels, each must be able, in spite of the united action of the other two, to move in its own direction. There is on the table a model in which the three wheels can take every possible position. To begin with, two large ones are placed opposite to, but independent of, one another, and parallel, and a small one, parallel to the others, is mounted between them at one end. This arrangement rolls along in a straight line with perfect freedom; on twisting the plane of the third wheel it is also free to roll round a curve whether the little wheel is before or behind. If I shift the position of one of the large wheels so that, though still parallel to, it is no longer opposite, the other, then, though they can freely move in a straight line, they can by no possibility be in duced to roll round a curve. It is clear, then, that two wheels that are parallel cannot be employed in a tricycle unless they are opposite one another. The only class of people who frequently appear to be familiar with this fact are nursemaids, who always tip up the front of a perambulator in turning a coner.

If one wheel is in front of and another behind a third, the combination can only roll round a curve when the front and rear wheel are turned to proportionate extents in opposite directions. The model is so arranged now ; if either of the little wheels is not turned to exactly the right amount, they can no longer roll, they can only be dragged round a curve. It is not sufficient that two parallel wheels should be opposite one another, they must be able to turn at different speeds. I have now the two large wheels keyed on the same axle, so that they must of necessity turn together; this combination is ready enough to go straight, but no amount of encouragement by the steering wheel will induce it to go in any other direction.

Bearing these facts in mind, it will not be difficult to follow the development of the tricycle. It would seem impossible in the first arrangement (that with two wheels opposite one another, and a third, or steering wheel, before or behind between them) to drive both sides, for the wheels must be able to turn at different speeds; let therefore one be free to go as it pleases, if the other only is driven, we have at once a very common form of tricycle, in which one wheel drives, one steers, and one is idle. 
Machines of this class have many defects. The feeble steering power, combined with their unsymmetrical driving, render them altogether untrustworthy. If any power is applied to the driver, which can only have its share of the weight upon it, it slips on the ground; if the machine is quickly stopped, owing to the small weight on the steering wheel, it is apt to swing round and upset; nevertheless, those who are content with pottering about on our wood pavement and gravel roads find this class of machine answer their purpose, and owing to their cheapness and simplicity they do not care to get a better.

The second arrangement of the model, in which riders must have recognised the Coventry Rotary, is free from most of the defects of the form just described ; there is more weight on the driver, but not enough to prevent its being made to slip round; there are two steering wheels a long way apart, with plenty of weight upon them, so that the guiding power in this type of tricycle is all that can be desired.

Let me now return to the first arrangement, in which two parallel wheels are opposite one anotber. If by any possibility both wheels could be driven, and yet be free to go at different speeds, then there being so large a weight on the drivers they could not be made to slip; the driving being symmetrical, most of the twisting strain would be taken off the steering wheel, and still the machine would be capable of folling round a curve with perfect freedom.

All the methods of solving the problem of double driving come under two heads, one depending on the action of a clutch and the other on differential or balance gear.

The clutch action being the simplest, I shall describe that first. In going round a corner the inner wheel must lag behind, or the outer wheel must run ahead of the other; as either wheel may be inner or outer according to the direction of the curve, each must be able to lag behind or each must be able to run ahead. If both were able to lag behind, the machine could not be driven forward, and it would be of little use ; if both were able to run ahead, the machine could not be driven backwards-a matter of small importance. There is on the table a large working model, showing how a four-sided wheel is free to revolve in a ring, but is instantly seized when turned the other way, owing to a jambing action on one or more of four rollers. The four-sided wheel then can be employed to drive the ring one way but not the other. One of these "clutches" or "friction grips" is placed at each end of the crank shaft in the "Cheylesmore" tricycle, and a chain round the ring of each drives the corresponding wheel. The machine named is a rear$\mathrm{s}$ eerer; the clutch is also employed in some frontsteerers.

The other method of double driving depends on the use of the well-known gear of three bevel wheels or of some equivalent mechanism. If the axle of the middle of the three wheels is turned round the common axle of the other two, the applied force is divided between those two wheels, yet the pair are free to move relatively. Let then the chain drive a wheel carrying the middle bevel, and let the side bevels be connected with the two drivers. Whatever happens, the power of the rider will be equally divided between them, yet the machine will be free to roll round a curve.

There are a great number of devices which are exactly equivalent to this the simplest of all, which is known as Starley's gear. There is on the table a beautiful model of the gear used in the Sparkbrook tricjcle, which has been lent me by the makers of that machine, Bown's differential gear, and some others; but time will not allow me to describe them. There is one gear, however, which presents many peculiarities, which 1 have devised, and which may be of interest. A large working model is on the table. Between the conical edges of two wheels which are connected to the drivers lie a series of balls, outside which is a ring with sloping recesses. If the ring be turned by a chain or otherwise, the balls jamb in the recesses as the rollers do in the clutch gear. Nevertheless they are free to turn about a radial axis, and so allow the two driven cone wheels independent motion. The bursting strain on the ring and the side thrust on the cones acting on rolling balls balance one another. With this gear the rider can cause the balls to jamb one way or both ways, and so have or avoid the "free pedal" as he pleases.

In almost all good designs of front-steering tricycles the power applied to the cranks is transmitted to a differential gear by a chain. The crank and connecting rod have also been used to transmit the power, but then the clutch is necessary.

There is, however, another type of tricycle, in which the use of cranks is avoided, among which may be mentioned the "Omnicycle," the "Merlin," and that highly ingenious machine, the rowing tricycle. On the table there is the Omnicycle gear. In all these the power is applied direct to the circumference of a wheel or sector, and so dead points are avoided, which is a point in their favour when meeting with much resistance. On the other hand, the sudden starting and stopping of the feet in the two former machines and of the body in the latter make this type utterly unsuitable for obtaining anything more than a moderate speed. In the Omnicycle ingenious expanding drums are employed, so that the power may be applied with different degrees of leverage according to circumstances.

There remains one type of tricycle whicb, for rapid running, surpasses many: I refer to what is known as the Humber pattern. So excellent is this form in this respect that the leading manufacturers have, by turning out machines on the same lines, paid the original makers a compliment which is not altogether appreciated. This pattern departs less from the ordinary bicycle than any other; it is one, in fact, in which, instead of one, there are two great wheels, giving width to the machine, between which the power is divided by the usual differential gear.

Having spoken of the differential gear and the clutch, I had better show the comparative advantages and disadvantages of the two methods of double driving. With the differential gear the same force is always applied to each wheel, so in turning a corner the outer one, which travels furthest, has most work expended upon it (work = force $X$ distance). In this respect the differential gear is superior. On the other hand, when one wheel meets with much resistance from mud or stones, and the other with hardly any, the latter has still half the strength of the rider spent upon it, which is clearly a mistake. With a clutch-driven machine running straight, the wheels take such a share of the rider's power as is proportional to the resistance they individually meet. When the machine is describing a curve, that is generally, only the inner wheel is driven, and the machine is for the time only a single driver, with the driver on the wrong side.

I must now describe some devices which are attracting much attention at the present time, the speed and power gears. Let us suppose there are two machines with wheels of different sizes, but in other respects alike. Then each turn will take the larger wheeled machine further than the smaller. In going up a hill the larger wheel will take its machine up a greater beight than the other in one revolution, which involves more work and therefore more strength. If on the large wheel the chain pulley were increased in size, then for the same speed of the treadles it would not turn so quickly, it would not take the machine so far up the hill as before, it would in fact be equivalent to a smaller wheel, so that less strength than before would be necessary. This diminution of speed, though of great advantage when climbing a hill, is the reverse on the 
level, for then very rapid pedalling would be necessary to maintain even a moderate speed. To obtain the advantage of high wheels or high gearing on the level and at the same time low wheels or low gearing on the hills, some highly ingenious devices are employed. On the table is a well-known one of these, the "Crypto-dynamic," which by a simple movement changes the relative speed of wheel and treadle Time will not permit me to describe the details of this arrangement, but it contains an epicyclic gear which is or is not in action according as the rider desires power or speed. There are several other devices having the same object, some depending on an epicyclic gear in a pulley, others on the use of two chains, only one of which is active at a time. These arrangements have the further advantage of enabling the rider to disconnect the treadles from the wheels whenever he pleases.

Tricycles on which two, three, or a whole family can go out for a ride together, involve few new principles, and I shall not for this reason have a word to say about them.

There remains one machine forming a class by itself, more distinct from all others than they are from one another. It is not a bicycle in the ordinary sense of the word; it is not a tricycle, for it has only two wheels. This machine is, from a scientific and therefore from your point of view, more to be admired than any other. It is called, after its inventor, the "Otto." The Otto bicycle and the Otto gas-engine will be lasting memorials to the ingenuity of the brothers who invented them.

No machine appears so simple, but is so difficult to understand as this. Tricyclists who have been in the habit of managing any machine at once, are surprised to find in this something which is utterly beyond them. They cannot sit upon it for an instant, for so soon as they are let alone it politely turns them off. When at length, after much coaxing, they can induce it to let them remain upon it, they find it goes the way they do not want. Riding the Otto, like any other accomplishment, must be learnt. Some seem at home on it in half an hour, others take a week or more. It is not surprising that that quick perception, in which ladies have so much the advantage of men, enables them to quickly overcome the apparently insurmountable difficulties which this machine presents to the beginner.

The rider when seated is above the axle of two large equal wheels; being then apparently in unstable equilibrium, he would of necessity fall forwards or backwards if some movement of recovery were not possible. The $C$ tto rider maintains his balance in the same way as the pedestrian. If he is too far forward, pressure on the front foot will push him back; if too backward in position, pressure on the rear foot will urge him forward. That this must be so is clear, for, whatever turning power be applies to the wheels, action and reaction being equal and opposite, they will produce an equal turning effect upon him. The steering of this machine is quite feculiar. In the ordinary way both wheels are driven by steel bands at the same speed; so long as this is the case, the Otto of necessity runs straight ahead. When the rider desires to turn, he loosens one of the bands, which causes the corresponding wheel to be free; if then he touches it with the brake or drives the other. wheel on, it will lag behind, and the machine will turn. It is even possible to make one wheel go forwards and one backwards at the same time, when the machine will spin like a top within a circle a yard in diameter.

There being no third wheel the whole weight is on the drivers, the whole weight is on the steerers; the frame, which is free to swing, compels the rider to take that position which is most advantageous, making him upright when climbing a hill, and comfortably seated when on the level. Owing to a curious oscillation of the frame which occurs in hill climbing, the dead points are eliminated, so the rider need not waste his strength at a position where labour is of no avail.

Though it has been impossible for me to do more than indicate in the most imperfect manner how numerous and beautiful are the principles and devices employed in the construction of cycles, I trust I have disappointed those who were shocked and horrified that so trivial a subject should be treated seriously in this Institution.

\section{DANGERS FROM FLIES}

$\mathrm{IN}$ a note communicated to the Gazzetta degli Ospitali for August I883, and republished in the current number of the Archives Italiennes de Biologie (tome iv. fasc. ii.), Dr. B. Grassi calls attention to the fact that fies are winged agents in the diffusion of infectious maladies, epidemics, and even parasitic diseases. During the summer season, when flies occur in swarms, it seems impossible to prevent them from settling on any and every object. In these countries, though sometimes troublesome, they are scarcely ever so numerous as in the warmer climates of the Continent, and even in these latter they are not often to be found such plagues as they are in Egypt; but in all these countries alike they may be seen to alight on all moist substances without distinction. It may be the expectorations of a phthisical or the ejecta of a tyrhoid patient that have last attracted these inquiring diptera ; but, irrespective of the material they may have been investigating, their next visit may be to the moist lips or eyes of a human being. Their feet, their mouth, and the pectoral portion of their bodies will have all come in contact with the infective mass, and will all in turn be more or less cleansed of it by the moisture of the freshly visited mucous membranes. But this danger has already been known and recognised, and it seems scarcely doubtful that in Egypt ophthalmia is constantly carried to the eyes of the infant natives by such winged visitors. Dr. Grassi calls our attention to even greater danger, and this from the ejecta of the flies themselves. Every housekeeper knows how the bright surface of a mirror or the gilt moulding of a picture-frame can be covered over with the little flecks left by these flies, no English words occur to us to translate therewith the phrase "les méfaits des mouches." The following experiences of Dr. Grassi relate to these:-At Rovellasca, between his laboratory, which is on a first floor, and his kitchen, which is on the ground floor, there lies a courtyard, with a distance between the windows of the two rooms of about ten metres. On a plate on the table of his laboratory he placed a large number of the eggs of a human parasite (Trichocephalus). After a few hours he found, on some white sheets of paper hanging in the kitchen, the well-known spots produced by the excreta of the flies, and on a microscopical examination of these spots, several eggs of the parasite were found in them. Some flies coming into the kitchen were now caught, and their intestinal tract was found quite filled with an enormous mass of facal matter, in which the presence of eggs of Trichocephali were detected. As it was practically impossible to keep all alimentary substances from contact with these flies, it follows that the chances of Dr. Grassi and his family being infected with Trichocephali were very great. As a matter of fact, the experiment was tried with non-segmented eggs of this worm. Another experiment was in the same direction. Dr. Grassi took the ripe segurents of a Tania solium (which had been in spirits of wine) and broke them up in water, so that a great number of the tapeworm's eggs remained susfended in the fluid. The flies came to the mixture, attracted by the sugar, and in about half an hour the ova of the tapeworms were to be found in their intestines and in the spots. Had these eggs been in a recent and living state, they would doubtless have been just as easily transported. To those who care to try these 